\title{
Prevalência de Salmonella spp. em suínos abatidos em um frigorífico do Distrito Federal determinada pela técnica de PCR
}

\author{
Prevalence of Salmonella spp. in slaughtered swine in the Federal District of Brazil, \\ as determined by the PCR technique
}

\author{
Rodrigo Oliveira Soares da Silva', Gislaine Gomes Gonçalves', Andrea Maria Lazzari², Fernanda Mulinari²* \\ 1 União Pioneira de Integração Social (UPIS), Curso de Mestrado em Ciência Animal, Brasília/DF - Brasil \\ 2 União Pioneira de Integração Social (UPIS), Departamento de Medicina Veterinária, Brasília/DF - Brasil
}

\section{*Corresponding Author}

Fernanda Mulinari, União Pioneira de Integração Social (UPIS), Departamento de Medicina Veterinária, Laboratório de Biologia Molecular, Fazenda Lagoa Bonita, BR 20, km 12, DF 335, km 4,8, CEP: 73750-980, Planaltina/DF - Brasil, e-mail: fermulinari@pq.cnpq.br

Cite as: Prevalence of Salmonella spp. in slaughtered swine in the Federal District of Brazil, as determined by the PCR technique. Braz. J. Food Technol., v. 21, e2017104, 2018.

Received: July 26, 2017; Accepted: Dec. 12, 2017

\section{Resumo}

A cadeia de produção suína vem crescendo assim como a exigência do fornecimento de produtos de qualidade, isentos de qualquer risco para os consumidores. A Salmonella spp. representa um risco biológico e é apontada como o agente responsável por diversos casos de doenças transmitidas por alimentos. O suíno é considerado um importante reservatório de Salmonella spp., o que torna imprescindível o conhecimento da dinâmica dessa bactéria em toda a cadeia de produção suína. Este trabalho foi realizado com o objetivo de determinar a prevalência de Salmonella spp. em suínos abatidos no Distrito Federal. Para isso, foram coletadas 240 amostras de linfonodos mesentéricos (LM) e 240 swabs de carcaça (SC) em um abatedouro com inspeção distrital. As amostras foram submetidas à PCR (Reação em Cadeia de Polimerase) para detecção da bactéria, revelando uma prevalência de $68,75 \%$ em LM de suínos abatidos e de 29,17\% em SC suína. A análise dos dados obtidos demonstrou que a distância entre granja de origem e abatedouro apresentou correlação positiva moderada com a prevalência de Salmonella spp. em LM de suínos abatidos. Foi constatada, ainda, uma correlação positiva fraca entre a prevalência de Salmonella spp. em LM de suínos abatidos e a prevalência de Salmonella spp. em SC. Esses resultados apontam a necessidade da implantação de programas de controle para diminuir a prevalência nos animais destinados ao abate, bem como evitar a contaminação cruzada nos estabelecimentos manipuladores de alimentos.

Palavras-chave: Método de diagnóstico; Porco; Reação em cadeia da polimerase; Bactéria.

\section{Abstract}

The production of pork has been increasing in recent years as well as the requirement for quality products, free of any hazard for consumers. Salmonella spp. represents a biological hazard and has been identified worldwide as the agent responsible for many cases of foodborne diseases. Swine are considered to be an important reservoir of Salmonella spp. and hence knowledge of the dynamics of the bacteria throughout the pork production chain is essential. The objective of this study was to determine the prevalence of Salmonella spp. in pigs slaughtered in the Federal District of Brazil. A total of 240 samples of mesenteric lymph nodes (LM) were collected and also 240 carcass swabs (SC), in a slaughterhouse submitted to official inspection. The samples were subjected to the PCR (Polymerase Chain Reaction) assay for bacterial detection, revealing a prevalence of $68.75 \%$ in the mesenteric lymph nodes of the slaughtered pigs and $29.17 \%$ in the SC. Moreover, the data analysis revealed that the distance between farm and slaughterhouse showed a moderately positive correlation with the prevalence of Salmonella spp. in the LM of the pigs at slaughter. A low positive correlation was also found between the prevalence of Salmonella spp. in the LM of the slaughtered pigs and the prevalence of Salmonella spp. in the SC. These results show the need to implement monitoring programs to reduce the prevalence in the animals sent to slaughterhouses and to avoid cross-contamination in food establishments.

Keywords: Diagnostic method; Pig; Polymerase chain reaction; Bacteria. 


\section{Introdução}

A qualidade microbiológica de carne e seus derivados pode ser afetada nas diversas fases do processo produtivo, o que compromete os aspectos relacionados à segurança dos alimentos e, consequentemente, causa impactos sobre a saúde pública. Entre os micro-organismos importantes para a qualidade e a segurança dos alimentos, destaca-se a Salmonella spp. por estar frequentemente relacionada a infecções alimentares (HURD et al., 2002).

A carne suína tem se mostrado um importante veículo de transmissão de Salmonella spp. e, tal fato, tem preocupado aos que se dedicam à cadeia de produção suína. Para conter a disseminação desse micro-organismo, controles sanitários devem ser implantados para monitorar a produção animal e a manipulação de produtos de origem suína (SANTOS et al., 2001a; LIMA et al., 2016).

Para tal, torna-se fundamental conhecer informações seguras relacionadas à dinâmica desse patógeno no processo produtivo, utilizando ferramentas adequadas e métodos de detecção cada vez mais sensíveis e específicos (BESSA et al., 2004; CASTAGNA et al., 2005).

As metodologias mais utilizadas para detecção de Salmonella spp. são os métodos bacteriológicos convencionais, de cultura e isolamento microbiológico, os ensaios imunológicos, representados pelos ensaios imunoenzimáticos baseados na técnica de ELISA (Enzyme Linked Immunoabsorbent Assay), e os moleculares, que têm como destaque a PCR - Reação em Cadeia da Polimerase (ANDRADE et al., 2010).

A técnica de PCR demonstra especificidade devido ao fato de detectar uma região única do genoma bacteriano e elevada sensibilidade na detecção do micro-organismo, já que a amplificação poderá ocorrer a partir de quantidades reduzidas de DNA (SANTOS et al., 2001a; OLIVEIRA et al., 2002; CASTAGNA et al., 2005).

No Distrito Federal, não há dados epidemiológicos disponíveis sobre a prevalência de Salmonella em rebanhos e produtos de origem suína. O objetivo deste estudo foi determinar a prevalência de Salmonella spp. em linfonodos mesentéricos (LM) e swabs de carcaça (SC) de suínos provenientes de diferentes locais do Distrito Federal, Mato Grosso e Mato Grosso do Sul abatidos em um frigorífico do DF, por meio do método de PCR, e disponibilizar esses dados para auxiliar na implantação de programas de controle higiênico-sanitários.

\section{Material e métodos}

A coleta das amostras foi realizada nos meses de outubro e novembro de 2011 e fevereiro e março de 2012. O número de amostras foi calculado pelo programa EPI INFO, fornecendo os seguintes parâmetros: número de animais abatidos sob inspeção distrital no DF (76.500 animais/ano), prevalência estimada (10\%) e intervalo de confiança de 95\%, considerando o nível de confiança de 99\%. Dessa forma, foram coletadas 240 amostras de LM e 240 amostras SC, totalizando 480 amostras.

Amostras de LM de onze lotes de suínos, oriundos do Distrito Federal e dos Estados do Mato Grosso (MT) e Mato Grosso do Sul (MS), e SC dos animais após o processo de abate foram coletados em um abatedouro localizado no DF, registrado no Serviço de Inspeção Distrital. Cada lote foi coletado em um dia.

De cada animal foi retirado o trato gastrointestinal, colocado em bandeja individual e levado a um local anexo à linha de abate, onde foi realizada a retirada da cadeia de LM. A coleta das amostras foi realizada de forma aleatória. Após a coleta, as amostras foram identificadas, acondicionadas em sacos plásticos individuais estéreis e conservadas sob refrigeração, em caixa térmica com gelo, durante o transporte até o laboratório, onde foram processadas no mesmo dia.

Após o procedimento de abate e antes do processo de resfriamento, amostras de SC foram coletadas de forma aleatória. Swab esterilizado foi friccionado nos sentidos vertical e horizontal sobre uma superfície de aproximadamente $100 \mathrm{~cm}^{2}$ nas regiões do membro posterior (medial) e abdômen (lateral). As amostras foram identificadas, mantidas sob refrigeração durante o transporte até o laboratório e processadas no mesmo dia.

As amostras de LM passaram por uma dissecação com retirada de tecidos adjacentes. Após, as amostras foram pesadas (20 g) e realizada uma descontaminação da superfície do LM dissecado por meio de flambagem. Essas amostras foram fracionadas em pequenos fragmentos e encaminhadas para a etapa de pré-enriquecimento não seletivo (200 mL de água peptonada tamponada 1\% - APT) no Laboratório de Microbiologia da UPIS (União Pioneira de Integração Social). As amostras de SC tiveram suas hastes retiradas e o segmento preservado foi encaminhado para a etapa de pré-enriquecimento não seletivo $(10 \mathrm{~mL}$ de água peptonada tamponada 1\% - APT). A incubação foi realizada a $37^{\circ} \mathrm{C}$ por $18 \mathrm{~h}$ a $24 \mathrm{~h}$ em estufa bacteriológica no Laboratório de Microbiologia da UPIS.

Para o enriquecimento seletivo, as amostras pré-enriquecidas foram homogeneizadas e, em seguida, uma alíquota de 0,1 mL de APT de cada amostra (LM e SC) foi adicionada a 9,9 mL do caldo Rappaport-Vassiliadis (CRV) e incubada a $37^{\circ} \mathrm{C}$ por 24h. Após a incubação, $1 \mathrm{~mL}$ de CRV foi separado para extração de DNA.

As amostras foram submetidas à extração de DNA no Laboratório de Biologia Molecular da UPIS por tratamento térmico, conforme metodologia adaptada de Santos et al. (2001b). Para isso, amostras de $1 \mathrm{~mL}$ de CRV foram centrifugadas a $3200 \mathrm{~g}$ por 4 min e o sobrenadante foi descartado. O sedimento foi então ressuspenso em $1 \mathrm{~mL}$ de tampão Tris-EDTA (Tampão de lise: $10 \mathrm{mM}$ de 
Prevalência de Salmonella spp. em suínos abatidos em um frigorífico do Distrito Federal determinada pela técnica de PCR Silva, R. O. S. et al.

Tris-HCl $(\mathrm{pH} \mathrm{8,0);} 100 \mathrm{mM}$ de NaCl; $1 \mathrm{mM}$ de EDTA; Dodecil Sulfato de Sódio - SDS 1\%) e submetido a uma nova centrifugação, sendo esse processo repetido duas vezes. Em seguida, o sobrenadante foi descartado e, por fim, o sedimento novamente ressuspenso em $100 \mu \mathrm{L}$ de tampão Tris-EDTA, incubando a $100{ }^{\circ} \mathrm{C}$ por 3 min para lise bacteriana. Depois da incubação, as amostras foram centrifugadas a $3.200 \mathrm{~g}$ por $4 \mathrm{~min}$, após o qual o sobrenadante foi removido e utilizado imediatamente para PCR ou armazenado a $-20^{\circ} \mathrm{C}$.

Para a reação de PCR, foram utilizados os primers 139 (5'GTGAAATTATCGCCACGTTCGGGCAA3') e 141 (5'TCATCGCACCGTCAAAGGAACC3'), que amplificam um fragmento de 284 pb do gene invA de Salmonella spp. (GALÁN et al., 1992; RAHN et al., 1992). Esse fragmento é comum para todos os membros do gênero Salmonella e ausente em outros gêneros. A PCR foi realizada utilizando $2 \mu \mathrm{L}$ de amostra, 2,5 mM de $\mathrm{MgCl}_{2}, 0,2 \mathrm{mM}$ de dNTPs, 0,5 $\mu \mathrm{M}$ de primer 139 e primer 141 e $1 \mathrm{U}$ de Taq DNA Polymerase (Fermentas ${ }^{\circledR}$ ), em um volume final de $25 \mu \mathrm{L}$. As reações foram realizadas em um termociclador T-100 Thermal Cycler Bio-Rad ${ }^{\circledR}$ usando as condições determinadas por Oliveira et al. (2002) com adaptações, de acordo com o seguinte protocolo: desnaturação inicial a $94^{\circ} \mathrm{C}$ por 5 min, seguindo por 35 ciclos de desnaturação a $94^{\circ} \mathrm{C}$ por $30 \mathrm{~s}$, anelamento do primer a $55^{\circ} \mathrm{C}$ por $30 \mathrm{~s}$ e uma extensão a $72{ }^{\circ} \mathrm{C}$ por $30 \mathrm{~s}$ e uma extensão final a $72{ }^{\circ} \mathrm{C}$ por $7 \mathrm{~min}$ em termociclador. Os produtos da amplificação foram separados por eletroforese em gel de agarose a 1,2\% contendo brometo de etídio, e utilizando um marcador molecular de $100 \mathrm{pb}$, os fragmentos amplificados foram visualizados em fotodocumentador EagleEye II Stratagene ${ }^{\circledR}$.

Um isolado clínico de Salmonella spp. do Laboratório de Bacteriologia da UPIS foi utilizado como controle positivo. Como controle negativo foi utilizada água purificada MilliQ, sendo tratadas da mesma forma, como as demais amostras.

Os dados de prevalência de Salmonella spp. em LM de suínos abatidos e em SC constatados neste estudo foram analisados por meio de estatística descritiva, utilizando o programa SAS Enterprise Guide. Os testes de correlação foram realizados segundo procedimento descrito por Santos (2007).

\section{Resultados e discussão}

O gênero Salmonella possui características peculiares que o tornam um patógeno bastante ofensivo para o homem. Os suínos, por sua vez, são considerados importantes reservatórios de Salmonella spp., funcionando como fonte de infecção para o humano de forma direta, devido à eliminação do agente nas fezes, ou indireta, por contaminação cruzada entre manipuladores ou equipamentos contaminados e carcaças ou produtos derivados ( $\mathrm{KICH}$ et al., 2005; LIMA et al., 2016).

Nesse contexto, a determinação da prevalência de Salmonella spp. em suínos destinados ao abate torna-se uma ferramenta imprescindível, pois disponibiliza dados epidemiológicos que poderão ser utilizados por programas de controle sanitário, evitando a chegada de animais portadores aos abatedouros.

No presente estudo, a análise das amostras de LM dos suínos abatidos no DF revelou uma prevalência de $68,75 \%$, constatada pela identificação de Salmonella spp. em 165 amostras de um total de 240, através de detecção molecular pela técnica de PCR. Avaliando separadamente a prevalência por lotes, o índice variou entre 28,57\% e 100\%, conforme demonstrado na Tabela 1.

Tabela 1. Prevalência de Salmonella spp. em linfonodos mesentéricos de suínos abatidos no DF por distância aproximada entre a cidade de origem e abatedouro.

\begin{tabular}{|c|c|c|c|c|c|}
\hline Lote & Cidade & Estado & $\begin{array}{c}\text { Distância } \\
\text { aproximada } \\
(\mathbf{k m})^{\star}\end{array}$ & $\begin{array}{l}\text { Número de } \\
\text { amostras }\end{array}$ & Prevalência \\
\hline 1 & Poxoreo & MT & 805 & 22 & $68,18 \%$ \\
\hline 2 & Dourados & MS & 1217 & 19 & $100,00 \%$ \\
\hline 3 & Poxoreo & MT & 805 & 20 & $70,00 \%$ \\
\hline 4 & Brasília & DF & 100 & 21 & $28,57 \%$ \\
\hline 5 & Brasília / Tapurah & DF / MT & - & 13 & $69,23 \%$ \\
\hline 6 & Brasília & DF & 100 & 21 & $38,10 \%$ \\
\hline 7 & Brasília / Prim do Leste & DF / MT & - & 21 & $66,67 \%$ \\
\hline 8 & Brasília / Prim do Leste & DF / MT & - & 21 & $95,24 \%$ \\
\hline 9 & Campo Verde & MT & 863 & 20 & $55,00 \%$ \\
\hline 10 & Campo Verde & MT & 863 & 21 & $90,48 \%$ \\
\hline 11 & Brasília & DF & 100 & 41 & $73,17 \%$ \\
\hline Total & & & & 240 & 68,75 \\
\hline
\end{tabular}

*O cálculo da distância aproximada foi realizado por rota traçada no Google Maps (2013). 
Verificou-se uma grande variação nos índices de prevalência de Salmonella spp. em suínos, no Brasil. Estudos demonstram prevalências variando de 16,6\% (SILVA et al., 2009) a 83,33\% (CASTAGNA et al., 2004), utilizando métodos bacteriológicos convencionais. Essa variação ocorre devido aos fatores regionais, manejo, animais e ao tipo de exploração utilizada. Também acarreta variações os diferentes métodos de detecção e os tipos de amostras analisadas, que apresentam resultados sob diferentes níveis de sensibilidade e especificidade para a bactéria pesquisada (BESSA et al., 2004; SILVA et al., 2009).

A elevada sensibilidade da técnica empregada neste estudo pode ter influenciado nos elevados índices de portadores detectados. Estudos comparativos demonstram a maior especificidade e sensibilidade da $\mathrm{PCR}$ em relação às técnicas convencionais (FRATAMICO, 2003; CASTAGNA et al., 2005; IBRAHIM et al., 2014).

No presente estudo, na análise do fator transporte sobre a prevalência de Salmonella spp. nos suínos destinados ao abate, tendo como base a distância entre a granja de origem dos animais e abatedouro e a prevalência encontrada, foi constatada uma correlação positiva moderada $(r=0,7)$. Para tal avaliação, os lotes 5, 7 e 8 foram excluídos, uma vez que eram lotes mistos formados por animais com duas origens. A correlação verificada sugere que a prevalência encontrada tende a ser maior quanto maior for a distância do transporte (Tabela 1).

Segundo Machado (2014), a infecção de lotes suínos pode ocorrer em qualquer fase da criação e a principal forma de infecção é fecal-oral, podendo a bactéria se alojar nos linfonodos e ser excretada quando o animal for submetido a um fator estressante, como o transporte, contaminando outros animais do mesmo ambiente.

A constatação de altos índices de prevalência de Salmonella spp. em suínos destinados ao abate é preocupante do ponto de vista sanitário, uma vez que a chegada de suínos portadores aos abatedouros pode resultar em contaminação cruzada (CASTAGNA et al., 2004; DANTAS, 2014).

Para avaliar a contaminação das carcaças dos animais utilizados neste estudo, foram realizadas análises de SC. A contaminação foi constatada por meio da presença de Salmonella spp. em 70 amostras das 240 analisadas $(29,17 \%)$. Na avaliação segmentada por lotes, a prevalência variou de $14,29 \%$ a $65 \%$, conforme relacionado na Tabela 2 .

A prevalência observada neste estudo apresenta-se elevada quando comparada aos estudos disponíveis em outras regiões do país. Em São Paulo, Teixeira (2006) analisou SC utilizando um método bacteriológico convencional e um ensaio imunoenzimático. Os resultados apontaram a presença de Salmonella spp. em 2,19\%
Tabela 2. Prevalência de Salmonella spp. em swabs de carcaça de suínos abatidos no DF.

\begin{tabular}{ccc} 
Lote & Quantidade amostra & Prevalência (\%) \\
1 & 19 & 15,79 \\
2 & 23 & 34,78 \\
3 & 19 & 21,05 \\
4 & 21 & 14,29 \\
5 & 13 & 23,08 \\
6 & 21 & 19,05 \\
7 & 21 & 52,38 \\
8 & 21 & 28,57 \\
9 & 20 & 65,00 \\
10 & 21 & 33,33 \\
11 & 41 & 19,51 \\
Total & $\mathbf{2 4 0}$ & $\mathbf{2 9 , 1 7}$ \\
\hline
\end{tabular}

e $12,08 \%$ das carcaças analisadas, respectivamente. Já em Santa Catarina, Seixas et al. (2009) pesquisaram a presença de Salmonella spp. em carcaças suínas em vários pontos da linha de abate, desde a escaldagem e depilação até a lavagem da carcaça. Nesse estudo, que utilizou uma técnica bacteriológica convencional para detecção, a bactéria pôde ser isolada em 9,72\% das amostras de SC. Neitzke et al. (2017), a partir da análise microbiológica, obtiveram uma frequência total de isolamento de Salmonella sp. igual a 7,75\% do total de amostras, em um frigorífico do Estado do Rio Grande do Sul, no período de abril a agosto de 2014.

Assim como na prevalência de Salmonella spp. em suínos destinados ao abate, existe uma grande variação nos índices encontrados na literatura mundial relacionados à contaminação cruzada dos produtos. Tal fato também parece estar relacionado aos diferentes métodos de detecção e tipos de amostras utilizadas, assim como ao variado índice de portadores que adentram ao abatedouro durante o processo produtivo (BESSA et al., 2004; SILVA et al., 2009; DANTAS, 2014).

Na avaliação dos índices de positividade encontrados neste estudo, a alta prevalência de Salmonella spp. nos suínos destinados ao abate parece ter contribuído para o índice elevado de contaminação cruzada nas carcaças, que apresentou uma correlação positiva fraca $(r=0,2)$ entre a prevalência de Salmonella spp. em LM e a prevalência de Salmonella spp. em SC.

Segundo Castagna et al. (2004), em situações em que existe a entrada constante de animais positivos na linha de abate, torna-se muito difícil evitar a contaminação.

Ao mesmo tempo, falhas na execução das boas práticas de fabricação de produtos de origem animal também colaboram para altos níveis de contaminação. Segundo Seixas et al. (2009), o isolamento de Salmonella spp. após o processo de abate pode estar relacionado à contaminação cruzada nas etapas de escaldagem, 
Prevalência de Salmonella spp. em suínos abatidos em um frigorífico do Distrito Federal determinada pela técnica de PCR Silva, R. O. S. et al.

depilação e evisceração, além da contaminação por facas e/ou manipuladores que não seguem as medidas preconizadas pelas boas práticas de fabricação.

A determinação da prevalência de Salmonella spp. em suínos abatidos no DF é um dado epidemiológico de relevância, pois contribui para a análise da dinâmica desse micro-organismo na cadeia de produção regional de suínos, tendo em vista que esses animais são considerados como reservatórios desse patógeno. Essa informação reforça a necessidade do controle da Salmonella spp., desde as granjas de criação até a expedição do produto final, uma vez que, além dos prejuízos causados por esse agente na produtividade do rebanho, a introdução de portadores pode aumentar o risco de contaminação do produto final e, consequentemente, os números de indivíduos acometidos pela infecção.

\section{Conclusões}

Os resultados obtidos revelaram uma prevalência média de $68,75 \%$ e $29,17 \%$ de Salmonella spp., respectivamente, em linfonodos e carcaça de suínos avaliados neste trabalho. O índice de prevalência da Salmonella spp. em LM apresentou correlação positiva moderada em relação à distância entre a granja de origem e o abatedouro e correlação positiva fraca com SC. A notificação dos dados de prevalência de Salmonella spp. em suínos destinados ao abate no DF, somados aos disponíveis em outros Estados, contribui para direcionar esforços na aplicação rigorosa de programas de controle higiênico-sanitário nos abatedouros e entrepostos, de forma a garantir a segurança dos alimentos da carne de origem suína e de seus derivados.

\section{Referências}

ANDRADE, R. B.; GEMELLI, T.; DALL ONDER, L. P.; CRISTINA, K.; BRITO, T.; BARBOZA, A. A. L.; BRITO, B. G. Métodos diagnósticos para os patógenos alimentares: Campylobacter sp., Salmonella sp. e Listeria monocytogenes. Arquivos do Instituto Biológico, v. 77, n. 4, p. 741-750, 2010. Disponível em: <http://www.biologico.sp.gov.br/docs/arq/v77_4/andrade. pdf>. Acesso em: 19 jun. 2013.

BESSA, M. C.; COSTA, M.; CARDOSO, M. Prevalência de Salmonella spp. em suínos abatidos em frigoríficos do Rio Grande do Sul. Pesquisa Veterinária Brasileira, v. 24, n. 2, p. 80-84, 2004. http://dx.doi.org/10.1590/S0100-736X2004000200006.

CASTAGNA, S. M. F.; MULLER, M.; MACAGNAN, M.; RODENBUSCH, C. R.; CANAL, C. W.; CARDOSO, M. Detection of Salmonella spp. from porcine origin: a comparison between a PCR method and standard microbiological techniques. Brazilian Journal of Microbiology, v. 36, n. 4, p. 373-377, 2005. http://dx.doi. org/10.1590/S1517-83822005000400013.
CASTAGNA, S. M. F.; SCHWARZ, P.; CANAL, C. W.; CARDOSO, M. R. I. Prevalência de suínos portadores de Salmonella sp. ao abate e contaminação de embutidos tipo frescal. Acta Scientiae Veterinariae, v. 32, n. 2, p. 141-147, 2004. Disponível em: <http://www.lume.ufrgs.br/handle/10183/19828>. Acesso em: 15 set. 2013.

DANTAS, S. T. A. Transferência de Salmonella enteritidis por contaminação cruzada e formação de biofilme em diferentes superfícies de corte. 2014. 52 f. Dissertação (Mestrado)-Instituto de Biociências de Botucatu, Universidade Estadual Paulista "Júlio de Mesquita Filho", 2014. Disponível em: <http://hdl.handle. net/11449/110355>. Acesso em: 22 set. 2013.

FRATAMICO, P. M. Comparison of culture, polymerase chain reaction (PCR), TaqMan Salmonella, and Transia Card Salmonella assays for detection of Salmonella spp. in naturally-contaminated ground chicken, ground turkey, and ground beef. Molecular and Cellular Probes, v. 17, n. 5, p. 215-221, 2003. http://dx.doi. org/10.1016/S0890-8508(03)00056-2. PMid:14580395.

GALÁN, J. E.; GINOCCHIO, C.; COSTEAS, P. Molecular and functional characterization of the Salmonella invasion gene invA: homology of invA to members of a new protein family. Journal of Bacteriology, v. 174, n. 13, p. 4338-4349, 1992. http://dx. doi. org/10.1128/jb.174.13.4338-4349.1992. PMid:1624429.

GOOGLE MAPS. 2013. Disponível em: <https://www.google. com.br/maps>. Acesso em: 22 set. 2013.

HURD, H. S.; MCKEAN, J. D.; GRIFFITH, R. W.; WESLEY, I. V.; ROSTAGNO, M. H. Salmonella enterica infections in market swine with and without transport and holding. Applied and Environmental Microbiology, v. 68, n. 5, p. 2376-2381, 2002. http://dx.doi. org/10.1128/AEM.68.5.2376-2381.2002. PMid:11976111.

IBRAHIM, W. A.; ABD EL-GHANY, W. A.; NASEF, S. A.; HATEM, M. E. A comparative study on the use of real time polymerase chain reaction (RT-PCR) and standard isolation techniques for the detection of Salmonellae in broiler chicks. International Journal of Veterinary Science and Medicine, v. 2, n. 1, p. 67-71, 2014. http://dx.doi.org/10.1016/j.ijvsm.2013.11.001.

KICH, J. D.; MORES, N.; PIFFER, I. A.; COLDEBELLA, A.; AMARAL, A.; RAMMINGER, L.; CARDOSO, M. Fatores associados à soroprevalência de Salmonella em rebanhos comerciais de suínos. Ciência Rural, v. 35, n. 2, p. 398-405, 2005. http://dx.doi. org/10.1590/S0103-84782005000200024.

LIMA, A. L.; RODRIGUES, D. P.; ARAÚJO, M. S.; REIS, E. M. F.; FESTIVO, M. L.; RODRIGUES, E. C. P.; LÁZARO, N. S. Sorovares e perfil de suscetibilidade a antimicrobianos em Salmonella spp. isoladas de produtos de origem suína. Arquivo Brasileiro de Medicina Veterinária e Zootecnia, v. 68, n. 1, p. 39-47, 2016. http://dx.doi.org/10.1590/1678-4162-7997.

MACHADO, G. B. Avaliação microbiológica e epidemiológica de causas de condenação e contaminação de carcaças e órgãos durante o abate de Búfalos e suínos, em frigoríficos de Pelotas e do Rio Grande do Sul/Gilmar Batista Machado. 
Prevalência de Salmonella spp. em suínos abatidos em um frigorífico do Distrito Federal determinada pela técnica de PCR Silva, R. O. S. et al.

2014. 50 f. Dissertação (Mestrado)-Programa de Pós-graduação em Veterinária, Faculdade de Veterinária, Universidade Federal de Pelotas, Pelotas, 2014

NEITZKE, D. C.; ROZA, C. R.; WEBER, F. H. Segurança dos alimentos: contaminação por Salmonella spp. no abate de suínos. Brazilian Journal of Food Technology, v. 20, e2015063, p. 1-7, 2017.

OLIVEIRA, S. D.; SANTOS, L. R.; SCHUCH, D. M. T.; SILVA, A. B.; SALLE, C. T. P.; CANAL, C. W. Detection and identification of Salmonellas from poultry-related samples by PCR. Veterinary Microbiology, v. 87, n. 1, p. 25-35, 2002. http://dx.doi.org/10.1016/ S0378-1135(02)00028-7. PMid:12079744.

RAHN, K.; GRANDIS, S. A.; CLARKE, R. C.; MCEWEN, S. A.; GALÁN, J. E.; GINOCCHIO, C.; CURTISS III, R.; GYLES, C. L. Amplification of an invA gene sequence of Salmonella typhimurium by polymerase chain reaction as a specific method of detection of Salmonella. Molecular and Cellular Probes, v. 6, n. 4, p. 271-279, 1992. http://dx.doi.org/10.1016/0890-8508(92)90002-F. PMid:1528198.

SANTOS, C. Estatística descritiva: manual de auto-aprendizagem. 2. ed. Lisboa: Silabo, 2007. 264 p.

SANTOS, L. R.; NASCIMENTO, V. P.; OLIVEIRA, S. D.; FLORES, M. L.; PONTES, A. P.; PILOTTO, F.; NEVES, N.; SALLE, C. T. P.; LOPES, R. F. F. Identificação de Salmonella através da reação em cadeia pela polimerase (PCR). Arquivos da Faculdade de Veterinária, v. 29, n. 2, p. 87-92, 2001a. Disponível em: <http:// www.ufrgs.br/actavet/29-2/santos.pdf>. Acesso em: 12 jul. 2013.
SANTOS, L. R.; NASCIMENTO, V. P.; OLIVEIRA, S. D.; FLORES, M. L.; PONTES, A. P.; RIBEIRO, A. R.; SALLE, C. T.; LOPES, R. F. Polymerase chain reaction (PCR) for the detection of Salmonella in artificially inoculated chicken meat. Revista do Instituto de Medicina Tropical de São Paulo, v. 43, n. 5, p. 247-250, 2001b. http://dx.doi.org/10.1590/S0036-46652001000500002. PMid:11696845.

SEIXAS, F. N.; TOCHETTO, R.; FERRAZ, S. M. Presença de Salmonella sp. em carcaças suínas amostradas em diferentes pontos da linha de processamento. Ciência Animal Brasileira, v. 10, n. 2, p. 634-640, 2009. Disponível em: <http://www.revistas. ufg.br/index.php/vet/article/viewArticle/3996>. Acesso em: 15 out. 2013.

SILVA, M. C.; FARIA, G. S.; PAULA, D. A. J.; MARTINS, R. P.; CARAMORI JUNIOR, J. G.; KICH, J. D.; COLODEL, E. M.; NAKAZATO, L.; DUTRA, V. Prevalência de Salmonella spp. em suínos abatidos no Estado de Mato Grosso. Ciência Rural, v. 39, n. 1, p. 266-268, 2009. http://dx.doi.org/10.1590/S010384782008005000035 .

TEIXEIRA, R. S. Detecção de Salmonella spp. em amostras de fezes, linfonodos e carcaças de suínos no momento do abate. 2006. 50 f. Dissertação (Mestrado Medicina Veterinária)Programa de Pós-graduação em Epidemiologia Experimental e Aplicada às Zoonoses, Universidade de São Paulo, São Paulo, 2006. Disponível em: <http://www.teses.usp.br/teses/ disponiveis/10/10134/tde-14052007-133108/pt-br.php>. Acesso em: 22 set. 2013. 